\title{
Erratum to: Light availability determines susceptibility of reef building corals to ocean acidification
}

\author{
D. J. Suggett $\cdot$ L. F. Dong $\cdot$ T. Lawson • \\ E. Lawrenz $\cdot$ L. Torres $\cdot$ D. J. Smith
}

Published online: 3 February 2013

(c) Springer-Verlag Berlin Heidelberg 2013

\section{Erratum to: Coral Reefs}

\section{DOI 10.1007/s00338-012-0996-7}

David Suggett, Tracy Lawson and David Smith conceived the study and wrote the paper; Liang Dong and Tracy Lawson constructed the CO2-stat facility, and (with
Lindzai Torres Santa Rosa) produced and analysed the experimental data; Evelyn Lawrenz and David Suggett collated and analysed the metadata set. David Suggett and Liang Dong are joint first authors.

L. T. Santa Rosa should be read as L. Torres.

The online version of the original article can be found under doi:10.1007/s00338-012-0996-7.

D. J. Suggett $(\bowtie)$ L. F. Dong · T. Lawson · E. Lawrenz ·

L. Torres - D. J. Smith

Coral Reef Research Unit, School of Biological Sciences,

University of Essex, Colchester CO4 3SQ, UK

e-mail: dsuggett@essex.ac.uk 